\title{
EFFECTS OF ESTRADIOL AND OXYTOCIN ON THE RELEASE OF PROSTAGLANDIN-LIKE SUBSTANCE FROM ISOLATED RAT UTERUS
}

\author{
Yoshio AIZAWA and Tadashige SHIMIZU \\ Department of Pharmacology, Tokyo College of Pharmacy, \\ Horinouchi, Hachioji, Tokyo 192-03, Japan
}

Accepted May 10, 1978

\begin{abstract}
Effects of estradiol on the release of prostaglandin-like substance (PG) from rat uterus was investigated. The amount of PG released into a medium that did not contain oxytocin was decreased by estradiol, but the release of PG was remarkably increased by the addition of oxytocin. No significant correlation was found in the relationship between $\mathrm{PG}$ release and uterine contraction in uterus of cither the ovariectomized rat and that of the estradiol-injected rat. The amount of PG released from the uterus of ovariectomized rat and the uterus of 6 hours after cstradiol injection was decreased by indomethacin. The PG release promoting action of oxytocin observed in estradiol-injected rat uterus disappeared completely with treatment of phospholipase C.
\end{abstract}

Prostaglandins are released from perfused uterus, spleen, lung, trachea, intestine and blood vessels (1-4). Vane and Williams (5) and Chan (6) reported that oxytocin promotes the release of prostaglandin from rat uterus, but these authors did not report differences in the effects of oxytocin on prostaglandin release at different stages of the estrogen level. Factors regarding the mechanism of prostaglandin release from rat uterus are obscure and there are reports stating that estrogen has an influence on prostaglandin biosynthesis in rat uterus $(7,8)$. The release of prostaglandin-like substance (PG) from rat uterus induced by oxytocin and the influence of estradiol on PG release were studied herein and we found that the amount of PG release induced by oxytocin was remarkably increased at 6 hours after estradiol injection. We also investigated the action of indomethacin an inhibitor of PGs biosynthesis $(9,10)$, and studied the effect of phospholipase $C$ in attempts to determine the relationship between the PG release and phospholipid increase noted a short time after estrogen injection (11).

\section{MATERJALS AND METHODS}

Wistar non-pregnant rats, weighing approx. $150 \mathrm{~g}$, were all ovariectomized the same day and maintained for 2 weeks. Ten , g estradiol in $0.1 \mathrm{ml}$ of sesame oil was given each rat subcutaneously, and the animals were decapitated at $0,6,12,24,48$, and 72 hours after estradiol injection, and the uteri isolated. Each uterus was mounted in a $2 \mathrm{ml}$ organ bath filled with Locke-Ringer solution, and connected to a strain gauge (Nihonkohden, SB-1T-H) provide with a $0.5 \mathrm{~g}$ of initial load. The uterus was incubated in $2 \mathrm{ml}$ of Locke-Ringer 
solution at $37^{\circ} \mathrm{C}$ and the isometric contraction was recorded. The incubation media were replaced three times every 15 minutes, and incubation in the organ bath was performed three times each for 15 minutes in the medium containing oxytocin $(10 \mathrm{mU} / \mathrm{ml})$. Each medium was collected and PG in the medium was extracted and determined by the following method.

\section{Identification of PG-like substance}

The uteri isolated at 6 hours after estradiol injection $(10 / / \mathrm{g} / \mathrm{rat})$ were used. Each uterus was incubated four times each for 15 minutes in the medium of $2 \mathrm{ml}$ containing oxytocin $(10 \mathrm{mU} / \mathrm{ml})$. These fluids were put together to make a total of $8 \mathrm{ml}$. The extraction of PGs from the medium was carried out as described under "Extraction and determination of PG". Extracts of PG from the medium were methylated with ${ }^{14} \mathrm{C}$-methanol according to the method described in our previous paper (12), and nonradioactive-PGF $\mathrm{P}_{2 \alpha}$ methylester and $\mathrm{PGE}_{2}$ methylester were added as carriers. Such were then applied to thin layer chromatography with silica gel as an absorbent, the solvent system consisting of ethyl acetate-methanol-water $(160: 25: 100)$. The methylester on the chromatogram was detected with iodine vapor, and the radioactivity was measured by a liquid scintillation counter.

\section{Extraction and determination of $P G$}

The medium $(2 \mathrm{ml})$ was acidified to $\mathrm{pH} 3.0$ with $0.1 \mathrm{~N} \mathrm{HCl}$, washed once with $4 \mathrm{ml}$ of petroleum ether, and then was extracted three times with $4 \mathrm{ml}$ of ethyl ether. The ether layer was washed once with $2 \mathrm{ml}$ of $0.01 \mathrm{~N} \mathrm{HCl}$ and once with $2 \mathrm{ml}$ water, and then evaporated under $\mathrm{N}_{2}$ gas current. The residue was dissolved with a small amount of ethanol and diluted by Tyrode solution, thus forming the total volume of $0.2 \mathrm{ml}$. The PG amount was determined by parallel bioassay using rat stomach fundus preparation according to the method of Vane (13). $\operatorname{PGF}_{2 \alpha}$ (Upjohn) was used as the standard substance.

\section{Treatment with indomethacin}

Indomethacin and estradiol were dissolved in sesame oil together with a small amount of acetone, and the acetone was removed by passing air through the mixture. Indomethacin $(10 \mathrm{mg} / \mathrm{kg}$ ) was given s.c. twice daily $\times 2$ while controls were given the vehicle alone. Estradiol $(10 / \mathrm{g} / \mathrm{rat})$ was given s.c. 6 hours before decapitation.

\section{Treatment with phospholipase $C$}

The uterus was incubated with phospholipase $C$ ( 4 units $/ \mathrm{ml}$ ) in $2 \mathrm{ml}$ of Locke-Ringer solution for 15 minutes. After incubation, this tissue was washed with the medium, and the amount of PG release into the medium was determined. Also, the uterus which was not treated with phospholipase $\mathrm{C}$ was incubated only with Locke-Ringer solution for 15 minutes and such served as the control. Phospholipase $\mathrm{C}$ obtained from Clostridium welchii (Sigma Chemical Co.) was used.

\section{RESULTS}

\section{Identification of $P G$-like substance released from rat uterus}

Fig. 1 shows the thin layer chromatogram of PG-like substance methylated by ${ }^{14} \mathrm{C}$ - 


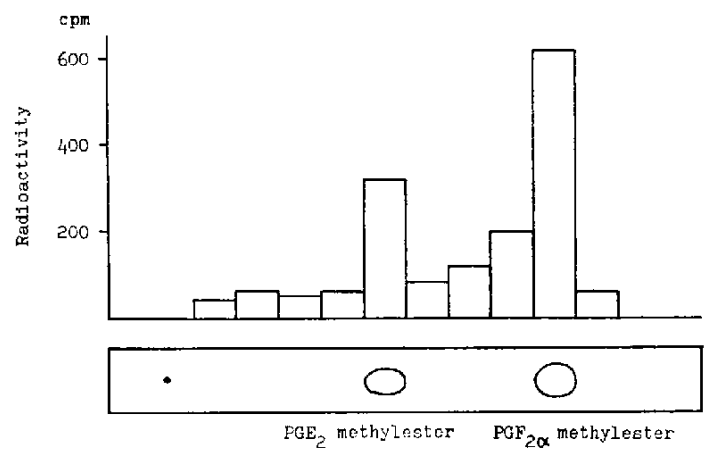

FIG. 1. Thin layer chromatogram of the substrances released from isolated rat uterus. The ovariectomized rat uteri at $6 \mathrm{hr}$ after estradiol injection were used in this experiment. The lower portion in the figure shows the spots of authentic $\mathrm{PGE}_{2}$ and $\mathrm{PGF}_{2 \alpha}$ methylesters. The upper portion illustrated by columns shows the radioactivity on thin layer chromatogram.

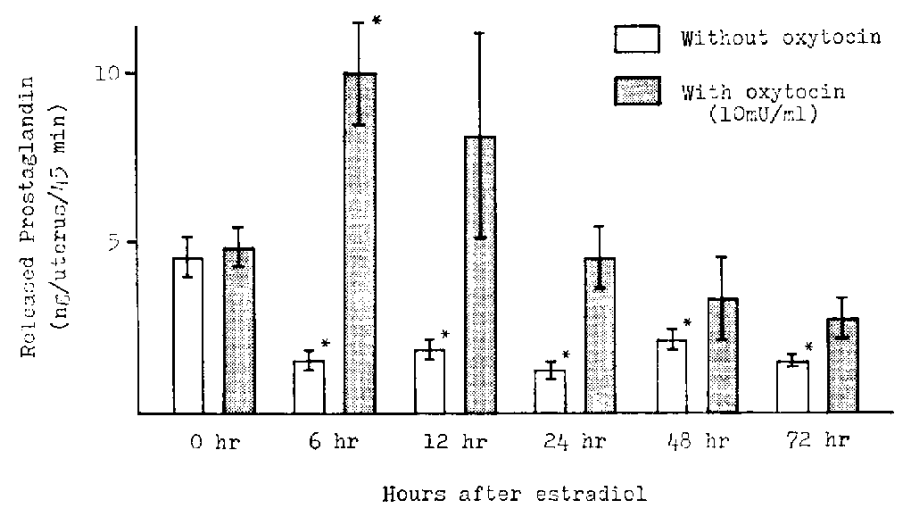

Fig. 2. Effect of oxytocin and estradiol on release of prostaglandin from isolated rat uterus. Each column represents the mean of 3 rats and the vertical line at the top represents standard error of the mean. *: Differs from zero hour $(\mathrm{p}<0.05)$

methanol. The results indicate that radioactivity on the thin layer chromatogram was recognized mainly in the parts corresponding to $\mathrm{PGF}_{2 \alpha}$ and $\mathrm{PGE}_{2}$. The highest radioactivity was observed in the same spot as $\mathrm{Rf}$ value of $\mathrm{PGF}_{2 \alpha}$.

2. Effect of oxytocin on $P G$ release from ovariectomized rat uterus and influence of estradiol on release of $P G$

As shown in Fig. 2, PG release from the ovariectomized rat uterus into the medium containing no oxytocin and into the medium containing oxytocin was almost the same. However, PG release from the uterus of 6 hours after estradiol injection into the medium not containing oxytocin was decreased, while PG release into the medium containing oxytocin was remarkably increased. This tendency was observed at 12 hours after estradiol injection, but the effect of oxytocin was sequentially decreased at 24,48 and 72 hours after estradiol injection. 


\section{Relationship between $P G$ release and uterine contraction}

Fig. 3 shows the relationship between the amount of $P G$ released by oxytocin and utcrine contraction. The correlation coefficient was low $(r-0.0167, n \cdots 48)$, and no significant correlation was recognized.

\section{Effect of indomethacin on release of $P G$ from rat uterus}

Since the greatest increase of $\mathrm{PG}$ release in rat uterus induced by oxytocin was observed at 6 hours after estradiol treatment, the uterine tissues from animals given estradiol injection 6 hours previously were used to determine the action of indomethacin on PG release. Fig. 4 shows the effect of indomethacin on PG release from uterus after estradiol injection and from ovariectomized rat uterus. In the ovariectomized rat uterus, PG release into the media containing no oxytocin and that containing oxytocin was decreased by indomethacin injection. In the uterine tissue from an animal given the estradiol injection, a similar decrease was observed. However, in the presence of oxytocin, there was still evidence of a slight stimulation of the release of $P G$.

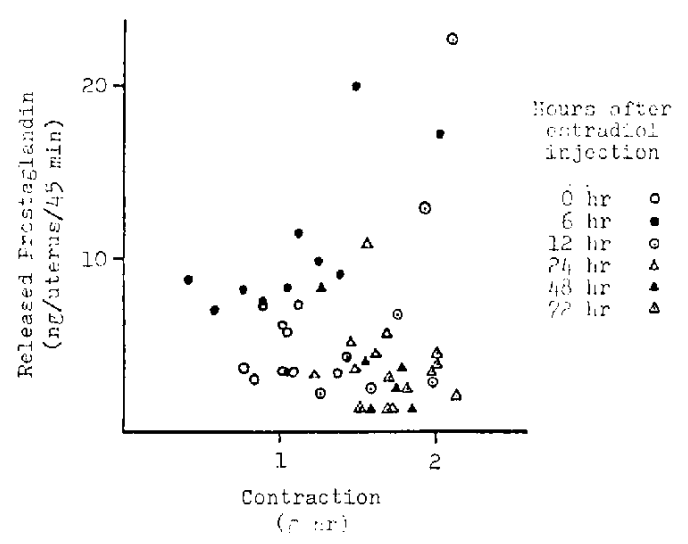

FIG. 3. Correlation between release of prostaglandin and rat uterine contraction. Contraction is expressed as the product of tension(g) and time (hr).

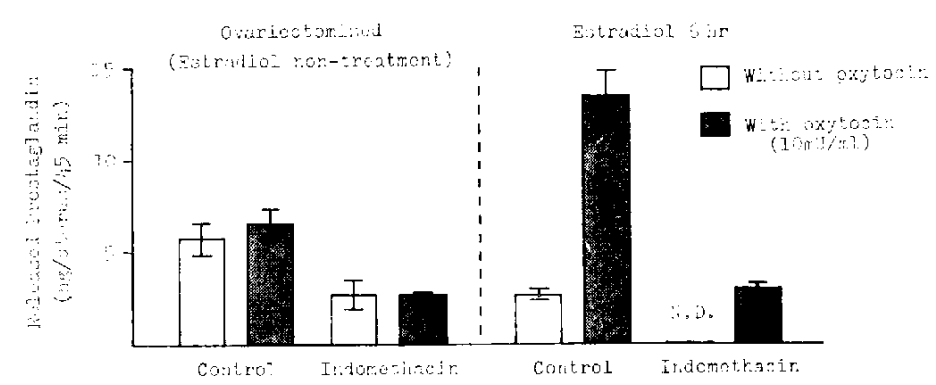

FIG. 4. Effect of indomethacin on release of prostaglandin from isolated rat uterus. Indomethacin $(10 \mathrm{mg} / \mathrm{kg})$ was injected s.c. twice daily $\times 2$. N.D.: Not detected. Height of a bar reprcsents an average of 3 rats and the vertical line through the bar represents standard error of the mean. 


\section{Influence of phospholipase $C$ treatment on $P G$ release from rat uterus}

PG release from uterine tissue into the medium containing no oxytocin was decreased in cases where estradiol injection had been given. However, PG release from estradiolinjected rat uterus was increased by phospholipase $\mathrm{C}$ treatment. Furthermore, addition of oxytocin increased PG release into the medium, but this increase was inhibited by phospholipase $C$ treatment.

\section{DISCUSSION}

The amount of PG release from the rat uterus into the medium containing no oxytocin was decreased in cases where estradiol injection had been given. In contrast, PG release due to oxytocin was accelerated by the hormone (Fig. 2). We reported previously that the PG content and the PG uptake of the rat uterus were increased in an early phase of estrogen action and PG biosynthesis in the tissue was not stimulated by estrogen treatment within 6 hours, but was stimulated 24 hours after the hormone injection (7). The effect of estradiol on $P G$ release from the uterine tissue (Fig. 2) into the medium containing no oxytocin is considered to be the result of acceleration of $P G$ uptake capacity in uterine tissue. As for the effect of estradiol on PG release under the condition containing oxytocin, it is considered that PGs accumulated in rat uterus by estradiol were released largely by oxytocin. Also, it seems that this effect of estradiol is closely related to an early effect of the hormone action. In addition, the tendency toward decrease in the $P G$ release with oxytocin 24 hours after estradiol injection may also be related to the activation of $P G$ catabolic enzyme increased by estrogen and as a result, PG content in rat uterus 24 hours after estrogen injection may have decreased as compared with that of 6 hours (7).

It has been reported that the uterine contraction by oxytocin is the result of the influence of PG $(5,6,14,15)$, but the results shown in Fig. 3 were not of proportional relation. The relationship between uterine contraction and $\mathbf{P G}$ release from uterus with oxytocin will require further study.

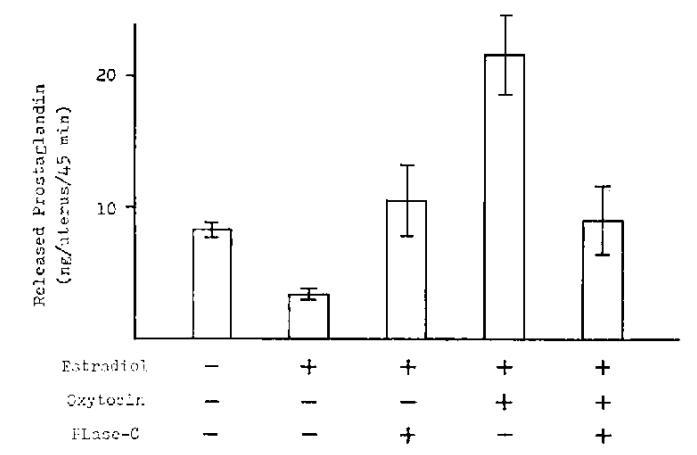

FIG. 5. Effect of phospholipase $C$ on the action of estradiol and oxytocin in the release of prostaglandin from isolated rat utcrus. PLase-C: Each isolated uterus was incubated with phospholipase $\mathrm{C}$ ( 4 units/ml) in $2 \mathrm{ml}$ of Locke-Ringer solution at $37 \mathrm{C}$ for $15 \mathrm{~min}$. Height of a bar represents an average of 3 rats and the vertical line through the bar represents standard error of the mean, 
Phospholipid in rat uterine tissue is one of the most sensitive organic components for estrogen (11), and is one of the main components of cell membrane. The effect of estrogen on the function of rat uterine cell membrane (e.g. sugar and amino acid transport) is significantly inhibited by treatment of phospholipase $\mathrm{C}$ which specifically catalyzes hydrolytic cleavage of phospholipid to diglyceride and corresponding phosphoryl products (16). It scemed of interest to study the role of phospholipid in the estrogen action and oxytocin effect on PG release from rat uterus. As shown in Fig. 5, both the estrogen action and the oxytocin effect on PG release from rat uterine tissue disappeared with phospholipase $C$ treatment. These results indicate that the decomposition of membrane phospholipid by phospholipase $\mathrm{C}$ treatment exerts a considerable influence on the amount of $\mathrm{PG}$ released. Thus, phospholipid in uterine tissue is related to the PG release mechanism in cell membrane function.

\section{REFERENCES}

1) Gilmore, N.J., Vane, J.R. and Wyllie, J.H.: Prostaglandins released by the spleen. Nature 218, 1135-1140 (1968)

2) Piper, P. ANd VANe, J.R.: The release of prostaglandins from lung and other tissues. Am. N. Y. Acad. Sci. 180, 363-385 (1971)

3) Yen, S.S., Mathe, A.A. and Dugan, J.J.: Release of prostaglandins from healthy and sensitized guinca-pig lung and trachea by histamine. Prostaglandins 11, 227-239 (1976)

4) Grodzinska, B., Panczenko, B. and Grycliwski, R.J.: Release of prostaglandin E-like material from perfused mesenteric blood vessels of rabbits. J. Pharm. Pharmacol. 28, 40-43 (1976)

5) VANT, I.R. AND WILLIAMS, K.I.: The contribution of prostaglandin production to contractions of the isolated uterus of the rat. Brit. J. Pharmacol. 48, 629-639 (1973)

6) Chan, W.Y.: Oxytocin-induced release of prostaglandin-like substance in isolated rat uterus. Life Sci. 14, 2385-2392 (1975)

7) Kogo, H., Yamada, K. and Aizawa, Y.: Effecl of estradiol on prostaglandin metabolism in rat uterus. Prostaglandins 13, 785-794 (1977)

8) Ham, E.A., Cirillo, V.J., Zanetri, M.E. and Kuehl, F.A. Jk.: Estrogen-directed synthesis of specific prostaglandins in uterus. Proc. natn. Acad. Sci. U.S.A. 72, 1420-1424 (1975)

9) VANE, J.R.: Inhibition of prostaglandin synthesis as a mechanism of action for aspirin-like drugs. Nature, New Biol. 231, 232-235 (1971)

10) Fiower, R.J., Gryglewski, R., Herbaczynska-Cfdro, K. and Vane, J.R.: Effects of anti-inflammatory drugs on prostaglandin biosynthesis. Nature, New Biol. 238, $104-106(1972)$

11) Aizawa, Y. Axd Mueller, G.C.: The effect in vivo and in vitro of estrogens on lipid synthesis in the rat uterus. $J$, biol. Chem. 236, 381-388 (1961)

12) AiZawa, Y. AND YAMADA, K.; Radioisotope dilution method for determination of prostaglandin $F_{2(x)}$ in rat tissue. Japan. J. Pharmacol. 24, 647-649 (1974)

13) VANF, J.R.: The use of isolated organs for detecting active substances in the circulating blood. Brit. J. Pharmacol. 23, 360-373 (1964)

14) ClegG, P.C., Hall, W.J. and Pickles, V.R.: The action of ketonic prostaglandins on the guinea-pig myometrium. J. Physiol. 183, 123-144 (1966)

15) BRLmmer, H.C.: Further studies on the interaction between prostaglandins and syntocinon on the isolated pregnant human myometrium. J. Obstet. Gynaec. Brit. Commonw. $79,526-530$ (1972)

16) Kogo, H. AND AlzAwA, Y.: Effect of phospholipase A, C, and D on sugar and amino acid transport in rat uterus. Japan. J. Pharmacol. 22, 411-415 (1972) 